\title{
Social dilemmas: When self-control benefits cooperation
}

\begin{abstract}
Individuals in a social dilemma may experience a self-control conflict between urges to act selfishly and better judgment to cooperate. Pairing a public goods game with a subtle framing technique, we test whether perception of self-control conflict strengthens the association between self-control and cooperation. Consistent with our hypothesis, cooperative behavior is positively associated with self-control in the treatment that raised the relative likelihood of perceiving conflict, but not associated with self-control in the treatment that lowered the likelihood. Our results indicate that self-control benefits cooperation.
\end{abstract}

Keywords: Cooperation; Self-control, Pro-social behavior, Public good experiment.

JEL Classification: D01, D03, D64, D70. 


\section{Introduction}

The social dilemma involves a tension between the individual rationality of self-interest and the collective well-being. However, it might also represent an internal tension, a conflict of preferences within the individual. We explore the social dilemma by conceptualizing the decision to cooperate as a conflict of preferences-between the impulse of greed and the better judgment to act pro-socially. As such, the question of acting selfishly or cooperatively becomes one of self-control, and the 'stronger' the individual, the more cooperation we would expect to observe. However, self-control matters only to the extent that the individual recognizes the decision at hand as a self-control conflict (Myrseth \& Fishbach, 2009). Following these ideas, Kocher et al. (2012) theorized about, and found evidence of, a positive correlation between the capacity for self-control and cooperation among participants who reported feeling conflicted during the contribution decision-but not among participants who reported no conflict. In this paper, we directly test the causality of conflict identification in the public good game.

We present a simple model of rational self-control in the public good game (for surveys on public goods experiments, see, e.g., Ledyard, 1995; Zelmer, 2003; Gächter, 2007; Chaudhuri, 2011). This model captures the conflict between cooperative (pro-social) and selfish behavior. Specifically, we model the internal conflict between free-riding and contribution to the public good as a two-stage decision problem; first, there is an identification stage and, second, a contribution stage; self-control ${ }^{1}$ determines the cost of cooperative behavior. Our framework for understanding cooperation is complementary to a range of other interpretations and findings. These include altruism, warm-glow, inequity aversion, efficiency preferences, reciprocity, logic of appropriateness, and the sheer confusion of individuals (see, for instance, Andreoni, 1990; 1995; Palfrey \& Prisbrey, 1997; Anderson et al., 1998; Fehr \& Schmidt, 1999; Houser \& Kurzban, 2002; Weber et al., 2004).

We test our model in a public good game, with experimental treatments to influence the identification stage in the self-control model; we do so by adopting the framing technique used by Martinsson et al. (2012) to influence perceived conflict in the dictator game (see also Myrseth \& Fishbach, 2010). Participants played a one-shot linear public goods game, of the Fischbacher et al. (2001) design, which elicits conditional contribution schedules through a variant of the strategy vector method (Selten, 1967), together with an unconditional contribution and an expectation of others' unconditional contributions. At the very end,

\footnotetext{
${ }^{1}$ We use the terms "willpower" and "self-control (effort)" synonymously.
} 
participants completed a measure of trait self-control (Rosenbaum, 1980a), and they also reported how conflicted they felt during the cooperation decision.

We find support for our main predictions. Identification of self-control conflict induced a stronger positive association between trait self-control and cooperation, as measured by unconditional and conditional contributions; participants in the framing treatment that prompted relatively higher likelihood of conflict identification exhibited a positive association between trait self-control and cooperation, but the participants in the treatment that prompted a lower likelihood of identification exhibited no correlation. Furthermore, an auxiliary test verifies that our treatments influenced perceived conflict as intended; participants in the treatment intended to raise the relative likelihood of conflict identification reported that they felt more conflicted during the decision to cooperate than did participants in the treatment intended to reduce the likelihood.

We organize the remainder of the paper as follows. Section 2 reviews the literature on the relation between pro-social behavior and self-control. Section 3 derives our predictions, and Section 4 explains our experimental design. We present in Section 5 the experimental results. Section 6 discusses our findings and concludes the paper.

\section{Self-control and pro-social behavior}

\subsection{Self-control and social dilemmas}

Long essential to psychologists' understanding of cognition, dual process theories are gaining ground in the study of economic behavior (Alós-Ferrer \& Strack, 2014). We adopt the dual process perspective and conceptualize self-control as a "cold" executive function that guides behavior in the face of "hot" impulses to act against better judgment (see e.g., Loewenstein, 1996; 2000; Metcalfe \& Mischel, 1999; O’Donoghue \& Loewenstein, 2007; Hofmann et al., 2009). As such, willpower represents the resources that the executive function wields in a struggle against temptation (see e.g., Baumeister et al., 1998). The resources may include cognitive strategies to divert attention away from temptation (Mischel, et al., 1989), strategies of pre-commitment (Thaler \& Shefrin, 1981; Schelling, 1984), or possibly the sheer strength of mind to hold back from the song of the sirens (Myrseth \& Wollbrant, 2013). 
The question of how pro-social versus selfish behavior relates to self-control was broached by Loewenstein $(1996 ; 2000)$, who suggests that selfish behavior may be motivated by visceral urges or drive-states, resembling cravings for relief from hunger, pain, and sexual deprivation. O'Donoghue and Loewenstein (2007) offer a conceptual framework for understanding how selfish urges may conflict with the "colder," more abstract preferences for altruism. ${ }^{2}$ Overall, recent empirical work is mixed, depending on experimental paradigms.

Most pertinent to our paper are studies on various forms of social dilemmas. Among these, fairly consistent evidence is reported from studies on time preferences. Curry et al. (2008) find in a standard public goods game that individuals' discount rates are negatively associated with their contributions to the public good. In other words, more "impatient" individuals contributed less to the public good than did "patient" ones. Fehr and Leibbrandt (2011) arrive at a similar pattern; they report that patient (vs. impatient) fishermenaccording to time preferences elicited in the lab-were in the field less likely to over-exploit the common pool resource. Moreover, Burks et al. (2009) report that "short-term" patiencethe $\beta$ in the $\beta-\delta$ model - is positively associated with cooperative behavior in a sequential prisoner's dilemma. ${ }^{3}$

Rand et al. (2012) and Rand et al. (2014), however, sound a contradictory message. Across a series of public good games, most administered online, they find that lower decision times are associated with more cooperative behavior and that time-pressure increases cooperation. They interpret this as evidence that giving is 'spontaneous' and greed 'calculated'. Similarly, Lotito et al. (2013) report that lower decision times are associated with more cooperation in a public good game, and Nielsen et al. (2013) find that free-riders, classified according to the Fischbacher et al. (2001) taxonomy of contributor types, exhibit longer decision times than do conditional cooperators. Tinghög et al. (2013), however, find no statistically significant effect of time-pressure in public good games, whereas Lohse et al. (2014) report the opposite pattern-that decision times are positively correlated with contributions. Because one could interpret the time-pressure treatment as a manipulation of cognitive resources, it is relevant to consider cognitive load treatments, which impair executive function by depleting cognitive resources; Duffy and Smith (2012) report no effect

\footnotetext{
${ }^{2}$ For an alternative conceptualization of the relationship between self-control and cooperation, see for example Rachlin (2004).

${ }^{3}$ For work in economics on self-control and time inconsistency, see e.g. hyperbolic and quasi-hyperbolic discounting models by Strotz (1955) and Laibson (1997), the "planner-doer" model by Thaler and Shefrin (1981), and the dual-self model by Fudenberg and Levine (2006) or the simplified version in Fudenberg et al. (2014). For work on procrastination, see e.g. O’Donoghue and Rabin (1999) and Burger et al. (2011).
} 
of cognitive load on outcomes across treatments in a repeated multi-player prisoner's dilemma. We conclude, therefore, that the state of empirical evidence on the relationship between cooperation and cognitive resources, also when conceptualized as decision times, is unclear.

Another recent empirical paradigm, which relies on a psychometric measure of trait self-control, shows that self-control and cooperation are positively correlated. In a one-shot, linear public good game, Kocher et al. (2012) tested a model of the relation between cooperation, self-control, risk-preferences, and the contributions of other players. Consistent with predictions from their model, cooperation are positively associated with the Rosenbaum (1980a) measure of trait self-control, and this association is moderated by risk-preferenceshigher risk aversion implies a weaker association. Moreover, using the conditional cooperation schedule elicited through the strategy method, they find that the level of cooperation by other players moderates this interaction. Also consistent with their model, the aforementioned patterns are obtained for individuals who reported feeling conflicted during the decision to cooperate - not for those who reported no conflict whatsoever. Notably, their study does not feature any experimental treatments - it is purely correlational. Our present paper, in contrast, tests the causality of conflict identification in a public good game, by manipulating experienced conflict during the decision to cooperate.

Finally, Myrseth et al. (2013) vary in the public good game the degree to which cash is tangible - and therefore more viscerally tempting - by representing cash either in physical form or solely on the computer screen. The authors find that the positive association between cooperation and Rosenbaum (1980a) trait self-control is stronger when cash is represented in physical form than when it is presented more abstractly, on the computer screen.

\subsection{Self-control and dictator games}

The pattern emerging from games that explore pure altruism is relatively similar to that from social dilemmas. Piovesan and Wengström (2009) measure decision times of participants in a repeated dictator game, lasting 24 periods. ${ }^{4}$ They find both across and within participants that shorter decision times are associated with more selfish choices. One interpretation of their results is that the default behavior is to act selfishly and that pro-social behavior requires the successful resolution of a self-control conflict. Such successful resolution of conflict would require cognitive resources, thereby raising response time.

\footnotetext{
${ }^{4}$ For a general discussion of the utility and merit of decision times in economics, see Rubinstein (2007).
} 
Accordingly, Achtziger et al. (2014a) manipulated cognitive resources in a 12-period dictator game. They find that depleting cognitive resources before the game reduced giving already in the first period. Moreover, giving in the 'low-depletion' treatment dropped as the rounds went on, converging in the final round on the amount given by players in the 'high-depletion' treatment. Similarly, Halali et al. (2013) report that cognitively depleted players in a fourperiod dictator game were less likely to give away half of their endowment. ${ }^{5}$ Hauge et al. (2009), however, report no effect of cognitive load on players in one-shot dictator games, consistent with Cornellisen et al. (2011), who report no main effect of cognitive load across three low-stake dictator games. ${ }^{6}$ Using a somewhat different experimental procedure-a repeated 'mini-dictator game', where participants face dichotomous choices between "fair" and "unfair" allocations-Schulz et al. (2014) point in a different direction: cognitive load raised the proportion of altruistic choices.

Martinsson et al. (2012) show that donations to the Red Cross in a one-shot dictator game are positively correlated with participants' scores on the Rosenbaum (1980a) measure of trait self-control. Moreover, the correlation was found in the framing treatment that was expected to raise the relative likelihood of identification of self-control conflict - not in the framing treatment that was expected to reduce the likelihood. Finally, Aguilar-Pardo et al. (2013) also report evidence of a positive relationship between self-control and altruistic behavior. In a dictator game featuring 4- to 6-year-old children, they find that children who donated candies in the dictator game also performed better on tasks of inhibitory control.

\subsection{Other evidence}

A growing literature on the "default" response in games of trust and reciprocity offers conflicting evidence. Achtziger et al. (2014b) subjected German players in an ultimatum game to cognitive resource depletion, and show that depleted proposers made lower offersthey became less altruistic. Moreover, depleted responders were more likely to reject offers that were unfair to themselves - they exhibited "altruistic punishment." The full pattern, however, reversed for Spanish participants, and, similarly, Halali et al. (2014) report that Israeli proposers made higher offers under cognitive depletion. Moving to neuroscience, Crockett et al. (2008) subjected responders to acute tryptophan depletion-a procedure that

\footnotetext{
${ }^{5}$ Players only had the option to give between 0 and $50 \%$ of their endowment.

${ }^{6}$ Cornellisen et al. (2011) break down the data according to Liebrand's (1984) measure of social value orientation (social preferences); cognitive load increased giving among individuals classified as "pro-socials", but that there was no effect among the majority of participants, classified as "pro-selves."
} 
temporarily reduces serotonin levels in the brain and thereby impairs self-control (Schweighofer et al., 2008); reduced serotonin levels raised rejection rates, and this reduction is positively correlated with impulsive choice in a delay-discounting task (Crockett et al., 2010). However, Knoch et al. (2006) report conflicting results. They subjected participants' right dorsolateral prefrontal cortex - thought to be responsible for executive functioning (Miller \& Cohen, 2001) - to low-frequency repetitive transcranial magnetic stimulation, in order to impair functioning in the targeted region. The authors find that responders under diminished executive functioning exhibited substantially lower rejection rates-less altruistic punishment.

In a trust game, Knoch et al. (2009) subjected receivers' right lateral prefrontal cortex to transcranial magnetic stimulation. The authors show that receivers, though aware that returning a share of the amount received was both strategic and norm-compliant, were unable to do so under impaired executive functioning; self-control seemed necessary to resist the temptation to keep the amount received entirely for oneself.

Finally, in a delay of gratification paradigm, Albrecht et al. (2011) show that individuals who chose for themselves between immediate and delayed rewards exhibited less patience and more affective involvement (activation in the dopaminergic reward system) than did individuals who made such choices for others-or for themselves in the future (for consistent results, see Pronin et al., 2008).

\section{Behavioral predictions}

\subsection{Utility}

Our empirical setting is a one-shot linear public goods game, where $\pi_{i}$ is the payoff, $e_{i}$ the endowment, $c_{i}$ the contribution level, and $\alpha$ the marginal return from the public good:

$$
\pi_{i}=e_{i}-c_{i}+\alpha \sum_{j=1}^{n} c_{j}
$$

Assuming $0<\alpha<1$ and $\alpha \cdot n>1$, this payoff function satisfies the requirements of a public good.

To derive our predictions, we analyze individually optimal behavior, treating the average contribution of other players in the public goods game as exogenously given. The 
average contribution by others is defined as $\bar{c}=\frac{1}{n-1} \sum_{j \neq i}^{n-1} c_{j}$. Because $\sum_{j=1}^{n} c_{j}=\bar{c}+c_{i}$, we can write $\pi_{i}\left(c_{i}, \bar{c}\right)=e_{i}-(1-\alpha) c_{i}+\alpha(n-1) \bar{c}$.

We assume an agent whose preferences are described by the utility function $U_{i}\left(c_{i}, \bar{c}\right)$ :

$$
U_{i}\left(c_{i}, \bar{c}\right)=\pi_{i}\left(c_{i}, \bar{c}\right)-s_{i}\left(c_{i}\right)-f_{i}\left(\bar{c}-c_{i}\right)
$$

The second component, $s_{i}\left(c_{i}\right)$, specifies the cost of exercising self-control. This cost is 'opportunity-based', as in Fudenberg and Levine (2006). The underlying idea is that temptation strength is proportional to the appeal of available alternatives. In this case, greed grows stronger when the difference between the highest available monetary payoff and the expected monetary payoff increases. Given $\bar{c}$, the difference between the highest conceivable monetary payoff (obtained by contributing zero) and the expected monetary payoff when contributing $c_{i}$ is $\pi_{i}(0, \bar{c})-\pi_{i}\left(c_{i}, \bar{c}\right)=(1-\alpha) c_{i}$. Assuming a linear functional form as in Fudenberg and Levine (2006), we write the cost of self-control as

$$
S_{i}\left(c_{i}\right)=\frac{(1-\alpha) c_{i}}{\omega_{i}}
$$

where the self-control cost is moderated by a willpower parameter $\omega_{i}>0{ }^{7}$

The third and final component, $f_{i}\left(\bar{c}-c_{i}\right)$, specifies a cost of deviating from the average contribution of others. We assume a standard quadratic cost function as in (4)

$$
f_{i}\left(\bar{c}-c_{i}\right)=\frac{\beta_{i}}{2}\left(\bar{c}-c_{i}\right)^{2}
$$

where $\beta_{i}>0$ is a parameter that measures sensitivity to deviations from mean contributions.

The motivation behind our approach is to describe an agent with altruistic motivations, but who nevertheless feels tempted to be selfish. That is, the agent experiences a self-control conflict between her better judgment to act pro-socially and the temptation to act selfishly. Moreover, to represent observed patterns of conditional cooperation (see, e.g. Fischbacher et al., 2001; Fischbacher \& Gächter, 2010), the agent experiences a cost from deviating from the

\footnotetext{
${ }^{7}$ Note that the self-control cost can be specified for any "cooperation default." We adopt for simplicity this assumption about behavior in the case of no identification. In the case of no identification, it does not matter qualitatively whether the agent is slightly altruistic, for example, due to decision heuristics. What is important, however, is that the agent will wish to be more cooperative in the case of identification.
} 
average contribution of others - the greater the deviation, the larger the cost experienced by the agent. Finally, to resolve this self-control conflict, the agent must expend costly effort. This effort is modeled with the approach by Fudenberg and Levine (2006), and implemented into the utility function accordingly. ${ }^{8}$

We can now state the utility function in full as

$$
U_{i}\left(c_{i}, \bar{c}\right)=e_{i}-(1-\alpha) c_{i}+\alpha(n-1) \bar{c}-\frac{(1-\alpha) c_{i}}{\omega_{i}}-\frac{\beta_{i}}{2}\left(\bar{c}-c_{i}\right)^{2}
$$

\subsection{The decision problem}

The agent's decision problem consists of two stages. At the identification stage, agent either identifies conflict with probability $p_{i}$ or does not identify conflict with probability $1-$ $p_{i}$. We denote conflict identification by $C \in\{0,1\}$, where $C=1$ indicates that the agent has identified conflict, and $C=0$ that the agent has not. If the agent identifies self-control conflict, she perceives the full utility function, while if she does not, she perceives only the utility from monetary payoffs, as in (6)

$$
U_{i}=\left\{\begin{array}{cl}
e_{i}-(1-\alpha) c_{i}+\alpha(n-1) \bar{c}-\frac{(1-\alpha) c_{i}}{\omega_{i}}-\frac{\beta_{i}}{2}\left(\bar{c}-c_{i}\right)^{2} & \text { if } C=1 \\
e_{i}-(1-\alpha) c_{i}+\alpha(n-1) \bar{c} & \text { if } C=0
\end{array}\right.
$$

Hence, if the agent does not identify self-control conflict, she is presumed entirely selfish, with a utility function that prescribes only profit maximization in the public goods game. ${ }^{9}$

If the agent does not identify conflict $(C=0)$, the optimal contribution is zero, $c_{i}^{*}(0)=0$. If the agent does identify conflict $(C=1)$, optimal contribution is given by $c_{i}^{*}(1)=\max \left(\bar{c}-k_{i}(\alpha), 0\right)$, where $k_{i}(\alpha)=\frac{(1-\alpha)}{\beta}\left(1+\frac{1}{\omega_{i}}\right)$. Hence, if average contributions of others are sufficiently large $\left(\bar{c} \geq k_{i}(\alpha)\right)$, the expected cooperation is given by

\footnotetext{
${ }^{8}$ Kocher et al. (2012) present a more generalized version of this model that incorporates risk preferences specified over monetary payoffs. Hauge (2010) employs a similar approach for the dictator game.

${ }^{9}$ This assumption is adopted for modeling convenience, but can of course be relaxed by including minor altruistic components of the utility function to allow for any "cooperation default," as long as the full utility function prescribes more cooperation than does the "selfish component." This assumption can thus be viewed as a simplifying normalization.
} 


$$
\hat{c}_{i}=p_{i}\left(\bar{c}-k_{i}(\alpha)\right)
$$

Consequently, as long as $\bar{c}>k_{i}(\alpha)$ holds, we predict the following:

PREDICTION 1: Given $\bar{c}>k_{i}(\alpha), \beta_{i}>0$, and $p_{i}>0$, higher levels of willpower $\omega_{i}$ are associated with higher levels of observed cooperation, and this association increases in the probability of identifying conflict $p_{i}$.

If the agent does not identify conflict, willpower is unrelated to cooperation, as the agent will only seek to maximize profit. However, if the agent has identified conflict, she holds prosocial motivations, and would prefer to cooperate when she knows that other group members, on average, cooperate. Because cooperation is costly also in terms of self-control, a higher level of willpower will allow the agent to cooperate more. Hence, we predict higher levels of cooperation $\hat{c}_{i}$ in the public goods game for higher levels of self-control. Furthermore, raising the likelihood of conflict identification $p_{i}$ leads more agents to identify conflict, and for these individuals self-control will be positively associated with cooperation. On the group level, therefore, we expect to observe that cooperation weakly increases in likelihood of conflict identification $p_{i}$.

PREDICTION 2: An increase in the average cooperation by other group members $\bar{c}$, raises $\hat{c}_{i}$ if $\beta_{i}>0$ and $p_{i}>0$ and leads to a strict increase only if $\bar{c}>k_{i}(\alpha)$

Because deviating from the average cooperation of others is costly to an agent with $\beta_{i}>0$ who has identified the self-control conflict, raising $\bar{c}$ will lead to weakly higher levels of cooperation $\hat{c}_{i}$, with a strict increase in cooperation if $\bar{c}>k_{i}(\alpha)$ held prior to the increase in average cooperation of others.

We further define the expected self-serving bias $B_{i}$ as the difference between the others expected contribution $\bar{c}$ and the agent's expected contribution $\hat{c}_{i}: B_{i}=\bar{c}-\hat{c}_{i} \cdot{ }^{10} \mathrm{We}$ can

\footnotetext{
${ }^{10}$ This is in line with terminology in the existing literature on cooperation, which defines the self-serving bias as the difference between "perfect conditional cooperation" (exactly matching others average contribution) and
} 
write this as $B_{i}=\left(1-p_{i}\right) \bar{c}+p_{i} k_{i}(\alpha)$, a convex combination of the average contribution of others and the personal parameter-determined threshold. Hence, we predict the following:

PREDICTION 3. Given $\bar{c}>k_{i}(\alpha), \beta_{i}>0$ and $p>0$, higher levels of willpower $\omega_{i}$ are associated with a smaller self-serving bias, and this effect increases in $p_{i}$, the probability of identifying conflict.

Though the difference between other's average cooperation $\bar{c}$ and own cooperation is costly to the agent who has identified self-control conflict, costly effort is required to reduce this difference. Therefore, we expect a small self-serving bias with higher levels of willpower. $^{11}$

\section{Experimental design and procedure}

\subsection{The public goods game}

The public goods game in our experiment relies on the following payoff function for individual $i$

$$
\pi_{i}\left(c_{i}, c_{-i}\right)=20-c_{i}+0.4 \sum_{j=1}^{4} c_{j}
$$

where $c_{i}$ denotes the contribution of individual $i$ to the public good. Each group consists of four randomly matched individuals, each individual receiving an endowment of 20 experimental points (the experimental currency unit). The marginal per capita return $\alpha$ from investing in the public good is 0.4 , meeting the requirements for a social dilemma. Assuming that participants are rational and self-interested, any $\alpha<1$ implies a dominant strategy to freeride. Because $\alpha \cdot n>1$, the socially optimal strategy is to contribute the entire endowment.

\footnotetext{
one's own contribution. The latter is commonly referred to as "imperfect conditional contribution," as contributions tend to imperfectly match those of others (see e.g., Fischbacher et al., 2012).

${ }^{11}$ Because contributions are a fixed amount below the contributions of others, the model implies that average conditional contributions are convex in average contributions by others, which is typically not observed. To account for the commonly observed pattern - a positive constant and a slope coefficient on average contributions by others less than one - the model would have to be adjusted. In particular, one might include a pure altruism component (to increase the constant when average contributions by others is low) and allow the self-control cost to depend on average contributions by others.
} 
The preference elicitation and the incentive mechanism in our experiment follow Fischbacher et al. (2001). Participants make two sets of decisions-first, an unconditional contribution to the public good and, thereafter, a conditional contribution schedule. The unconditional contribution is in the form of a single integer, $0 \leq c_{i} \leq 20$. For the conditional contribution, participants indicate how much they would contribute to the public good for any possible average contribution (rounded to integers) of the other three players within their group. For each of the 21 possible averages from 0 to 20, participants decide on a contribution between (and including) 0 and 20. This is a version of the strategy vector method (Selten, 1967).

To achieve incentive-compatibility, both conditional and unconditional contributions are potentially payoff-relevant. For one group member, randomly selected by the toss of a four-sided die, ${ }^{12}$ the payoff depends on conditional contribution; for the other three members, payoffs depend on unconditional contributions. In other words, the three unconditional contributions within a group, and the corresponding conditional contribution (for the average of the three unconditional contributions), constitute the sum of contributions to the public good. One may then compute individual earnings, according to equation (8).

\subsection{Treatments}

To test our hypothesis, we employed three between-subject treatments - the isolated, the standard, and the interrelated treatments - to influence perception of choice context and hence identification of self-control conflict. We ran two sessions per treatment, and participants were randomly assigned to one of the six sessions.

The isolated and interrelated treatments were implemented with a subtle framing procedure designed by Myrseth and Fishbach (2010) to influence identification of self-control conflict, and adapted to the dictator game by Martinsson et al. (2012). Participants viewed a calendar showing the present month, and the calendar contained either a grid that separated the dates or no such grid (see Figure 1). Moreover, in the gridded calendar, the date of the experiment was highlighted in grey; the date was not highlighted in the non-gridded calendar. Because we expected those who saw the gridded calendar to adopt a more isolated view of their subsequent choice opportunities, we refer to this treatment as the isolated treatment. Conversely, because we expected participants who saw the calendar with no grid to adopt a

\footnotetext{
${ }^{12}$ Each group member is assigned a number from one to four. A randomly selected participant rolls the die, and the roll of the die is monitored by the experimenter.
} 
less isolated view - the choice opportunities perceived more related to each other-we refer to this as the interrelated treatment. We denote as the standard treatment that which features no calendar and otherwise resembles the typical presentation of the public good game. ${ }^{13}$

\section{Insert Figure 1 about here}

The purpose of this procedure was to manipulate participants' perception of the decision context, without actually changing the decision itself. As such it can be thought of as a framing treatment. Originally, Myrseth and Fishbach (2010) designed this framing technique to influence identification of self-control conflict in the face of "epsilon cost temptation." Epsilon cost temptations are tempting behaviors for which unit consumption cost is marginal — such as the calories gained from a single cookie-but for which long-run aggregated costs nevertheless may prove more severe - such as an expanding waistline. The authors argue that the gridded relative to the non-gridded calendar activated an isolated (versus interrelated) frame of the choice opportunity; participants were more likely to isolate the date in question and thus less likely to see the decision task in relation to similar future opportunities. Consequently, the gridded calendar reduced the relative likelihood that participants would identify a conflict between the temptation to have chips and the better judgment to maintain a fine figure and good health. And, as argued by Myrseth \& Fishbach (2009), individuals will go for the temptation by default, if they never identify self-control conflict in the first place. In other words, self-control resources - or willpower-are only relevant to the extent that individuals have identified self-control conflict.

Martinsson et al. (2012) adapted this argument to the context of the dictator game, making the case that greed in low-stake allocation decisions also might take the form of epsilon cost temptation. That is, the question of whether or not to be generous - to donate to a charitable organization - may elicit self-control conflict if the decision is viewed in relation to future decisions, but not if the decision is viewed in isolation. If viewed in relation to future decisions, the question of how much to donate on a single occasion may have bearing on the decision maker's self-image; donating now-and in the future-indicates a generous character, whereas keeping the money for oneself does not. However, if viewed in isolation,

\footnotetext{
${ }^{13}$ A priori, we could not be sure how the view of participants in the standard treatment would compare to those of participants in the other two treatments - this would depend on the "default" view they had coming into the experiment and on the framing of the standard treatment itself. However, a reasonable guess was that the participants in the standard treatment would fall somewhere between the narrow view in the isolated treatment and the wide view in the interrelated treatment, as was the case with donations in Martinsson et al. (2012).
} 
the question of how much to donate has little bearing on self-image; the present decision of how much to donate is considered only in light of immediate consequences, leaving selfimage out of the equation. Because a consistent self-image represents an important motivator for pro-social behavior (see e.g., Bénabou \& Tirole, 2011; Gneezy et al., 2012), they expected that individuals more likely would identify self-control conflict between selfish and pro-social behavior if the allocation decision was seen in relation to future opportunities than if it is seen in isolation. This mechanism is also consistent with the "logic of appropriateness" framework, which assumes that individuals ask themselves, "What does a person like me do in a situation like this?" (e.g., March, 1994; Messick, 1999; Weber et al., 2004). We assume that a person "like me" sees little harm in being selfish once, but holds a more altruistic objective when behavior is viewed more generally. Our framework can then be viewed as specifying when a particular logic of appropriateness is activated, thereby triggering a self-control conflict. Using the treatment by Myrseth and Fishbach (2010), Martinsson et al. (2012) found support for these ideas. Participants in the interrelated treatment - which presented a calendar without a grid - exhibited a positive correlation between the Rosenbaum (1980a) measure of trait selfcontrol and donations. However, there was no correlation among participants in the isolated treatment — which presented a calendar with a grid.

For the same reasons that the framing treatment may influence self-control conflict in the dictator game, it may also influence self-control conflict in the public good game.

\subsection{Measurement of conflict identification and of trait self-control}

As argued by Myrseth and Fishbach (2009), the capacity to exercise self-control is relevant to the decision to indulge only when the individual has identified self-control conflict. Therefore, one approach to investigating whether the problem of pro-social versus selfish behavior resembles one of self-control is to test whether capacity for self-control is positively associated with pro-social behavior when the individual has felt conflicted, but less so or not at all when the individual has not. This is the approach taken in this paper, and by Martinsson et al. (2012) in a dictator game and in a recent follow-up paper by Kocher et al. (2012) using a public good game. Martinsson et al. (2012) made the argument by subjecting participants to different treatments - those discussed in the treatment section above-intended to manipulate the relative likelihood of conflict identification. The authors found that capacity for self-control was positively associated with donations in the treatment intended to raise likelihood of conflict identification, but not in the treatment intended to reduce the likelihood. 
Kocher et al. (2012), however, did not subject participants to any experimental treatment. Rather, their results rely on a measurement of experienced conflict. They found that capacity for self-control was positively related to cooperation among participants who reported feeling conflicted during the contribution decision, but not among participants who reported no conflict. Our present paper seeks to test the causality of conflict identification in the public good, unresolved in Kocher et al. (2012), by importing the experimental treatment from the dictator game by Martinsson et al. (2010). We also included the conflict measure from Kocher et al. (2012) to verify the treatment and to replicate the pattern obtained by them.

To capture subjectively experienced strength of conflict, we presented a question in the last part of the experiment similar to one used in Aaker et al. (2008) and identical to that used in Kocher et al. (2012): "To what extent did you experience conflict when deciding how much to contribute?" Participants answered this question on a continuous scale ranging from 0 ("not at all") to 140 ("very much").

To capture capacity for self-control, we implemented a standard measure of trait selfcontrol - the Rosenbaum Self-Control Schedule (Rosenbaum, 1980a), henceforth abbreviated Rosenbaum. ${ }^{14}$ This measure has been validated against a series of relevant personality measures, and against behavioral tasks associated with self-control, such as resisting pain (Rosenbaum, 1980b), coping with stress (Rosenbaum \& Smira, 1986; Rosenbaum, 1989), coping with mental disability (Rosenbaum \& Palmon, 1984), coping with seasickness (Rosenbaum \& Rolnick, 1983), quitting smoking (Katz \& Singh, 1986), saving over spending (Romal \& Kaplan, 1995), and curtailing procrastination (Milgram et al., 1988). More recently, the measure has been found under certain conditions to correlate positively with prosocial behavior-specifically, donations in a dictator game (Martinsson et al., 2012) and cooperation in a one-shot public good game (Kocher et al., 2012).

An extensive literature from personality psychology documents that the tendency to apply self-control represents a stable trait within the individual over time. Perhaps most dramatically, Mischel and colleagues report that a child's performance at age 4 on an instant gratification task (e.g., one marshmallow now, or two marshmallows later) predict later in life their cognitive control (Eigsti et al., 2006), ability to concentrate, self-control, interpersonal competence, SAT scores, and drug use (Mischel et al., 1988; Mischel et al., 1989; Shoda et al., 1990; Ayduk et al., 2000). To top it off, Duckworth and Seligman (2005) found that a

\footnotetext{
${ }^{14}$ The Rosenbaum Self-Control Schedule (1980a) is included in Appendix B.
} 
composite measure of trait self-control, administered among eighth-graders in the fall, exceeded IQ as a predictor of academic achievement in the following spring.

\subsection{Overview of procedure}

We recruited participants from undergraduate classes at a university in Medellín, Colombia, in 2008. The head administrator sent to the university email lists invitations to participate in economic experiments, and she posted posters on campus, as well. In addition, the experimenter introduced himself in classes, where he repeated the information from the emails. We held six sessions - two sessions for each treatment-with 24 participants per session. Nobody participated in more than one experimental session, and none were students of mathematics, psychology, or economics. Participants entered a lecture hall, after which they were provided an experimental id-number to ensure anonymity, and assigned a seat. The experiment started with the experimenter distributing instructions for the public goods game (see Appendix A). The experimenter read the instructions aloud to participants. ${ }^{15}$ When finished, all participants completed a set of control questions - to ensure comprehension. Participants were allowed to ask questions in private; when all had finished, the questions were solved in public on a black board. Thereafter, the experimenter distributed decision sheets for the public good game. The first page of the decision sheet was blank for all participants. The second page was either blank or contained a calendar, depending on treatment. The third page contained the answer sheet for the public good game; here the participant reported the amount she wished to contribute unconditionally. Once participants had indicated their decisions, the experimenter collected the decision sheets and distributed a second decision sheet; the participants were asked to provide an incentivized guess of how many tokens on average the other participants in the same session had contributed. Once participants had indicated their guess, the experimenter collected the decision sheets and distributed a third decision sheet; the participant indicated how much they wished to contribute conditionally, by completing a contribution table, as in Fischbacher et al. (2001).

When participants had indicated their conditional contributions, the experimenter collected their decision sheets and distributed a questionnaire. The questionnaire first included a question that asked about the degree of conflict experienced during the allocation decisions.

\footnotetext{
${ }^{15}$ All instructions and materials were translated into Spanish and presented to participants as such. At the time, we were unaware of other Spanish translations of the Rosenbaum Self-Control Schedule (Rosenbaum, 1980a), such as the validated translation presented in Capafóns (1989). We thus produced our own translation, but it does not differ substantially_see Appendix B. Our translation is identical to that used by Martinsson et al. (2012).
} 
Second, it presented the Rosenbaum Self-Control Schedule (1980a), and finally it posed some socioeconomic questions. Upon completing the questionnaire, participants exited the room, lined up, and re-entered the room one-by-one to claim their payment in private.

\section{Experimental results}

The summary statistics in Table 1 show that both conditional and unconditional contributions in our sample resemble those reported elsewhere (e.g., Fischbacher et al., 2001; Fischbacher \& Gächter, 2010). Moreover, the Rosenbaum scores are roughly similar to those found in other studies. ${ }^{16}$

\section{Insert Table 1 about here}

As expected, unconditional contributions are higher in the interrelated treatment (Mean $=8.71)$ than in the isolated treatment $($ Mean $=8.05)$, but this difference is not significant, $p=$ 0.63 (Mann-Whitney $U$ ). Finally, there is no significant difference in Rosenbaum between the interrelated $($ Mean $=29.41)$ and isolated $($ Mean $=31.51)$ treatments, $p=0.64$ (Mann-Whitney $U)$.

\subsection{Conditional contributions}

Our experiment elicited both conditional and unconditional contributions to the public good. We start by analyzing conditional contributions.

With the vector strategy method, each participant indicated 21 contribution levels for all possible average contribution levels (rounded to integers) of the other group members. The elicitation schedule was fully incentivized. Testing Predictions 1 through 3, Table 2 presents an OLS analysis of the conditional contributions as a function of Rosenbaum scores and average contributions by others (denoted Others). For simplicity of exposition, we break down our analysis by treatments.

\footnotetext{
${ }^{16}$ The grand mean is slightly above the corresponding range of means from the original samples studied by Rosenbaum (1980a, b) - Mean = 29.7 vs. Means ranging from 23 to 27. It is above that (Mean=16.7) obtained in Germany by Kocher et al. (2012), but close to that (Mean $=32.1$ ) obtained in Colombia by Martinsson et al. (2012).
} 
All specifications replicate a commonly found pattern - that the level of others' average contributions is strongly associated with own contributions (e.g., Gächter, 2007; Kocher et al., 2008; Fischbacher \& Gächter, 2010; Kocher et al., 2012). ${ }^{17}$

Consistent with Prediction 1, specifications (7) and (8) reveal a positive and significant coefficient ( $p$ 's $<0.05$ ) on the Rosenbaum main effect; in the interrelated treatment, trait selfcontrol is positively associated with cooperation. However, the corresponding main effects for the isolated and standard treatments - in specifications (1-2) and (4-5), respectively-are not significant ( $p$ 's $>0.77$ ). This latter result is also consistent with Prediction 1, which states that the positive association between self-control and cooperation increases in the probability of identifying self-control conflict.

In line with Prediction 2, specifications (2), (3), (5), (6), and (8) yield a positive and significant coefficient on the Others main effect. That is, contributions increase in the amount contributed by other players.

Specification (9) provides support for Prediction 3. The coefficient on the interaction between Rosenbaum and Others is positive and significant $(p<0.01)$. This means that the self-serving bias - the discrepancy between what others contribute and what the player contributes-diminishes with self-control in the interrelated treatment. Furthermore, the corresponding coefficients for the isolated and standard treatments - in specifications (3) and (6), respectively - are not significant, ( $p$ 's $>0.37$ ). This is also consistent with Prediction 3 , which states that the self-serving bias should diminish with self-control more sharply with a higher likelihood of identifying self-control conflict.

\section{Insert Table 3 about here}

In the aforementioned analyses, we have broken the data down by treatments. To directly test the differences in the interaction effects found in Table 2 on specifications (3), (6) and (9), we provide the full specification in Table 3 (specification 10), which includes the treatments as variables. This also provides a direct test of Prediction 3, which states that the association between cooperation and the Rosenbaum-Others interaction is stronger in the

\footnotetext{
${ }^{17}$ In Kocher et al. (2012), the main effect of others' average contributions disappears in a regression analysis that includes risk preferences, but is otherwise similar.
} 
interrelated than in the isolated treatment. Consistent with Prediction 3, the coefficient on the interaction between Rosenbaum, Others, and Isolated, in specification (10), is negative and significant $(p<0.05)$, while the interaction between Rosenbaum and Others positive and significant $(p<0.01)$ (recall that the Interrelated treatment represents the baseline in specification 10). This result verifies that the self-serving bias diminishes with self-control more sharply in the interrelated than in the isolated treatment.

We summarize our results below, according to Predictions 1-3, respectively:

RESULT 1a: In the interrelated treatment, there is a positive association between levels of trait self-control and conditional cooperation, but there is no discernable association in the isolated treatment.

RESULT 2: There is a positive association between conditional cooperation and the average cooperation by others.

RESULT 3: In the interrelated treatment, there is a negative association between the degree of self-serving bias and levels of self-control, but there is no discernable association in the isolated treatment.

Our results are of economic significance; the marginal effect in the interrelated treatment of Others is: $0.215+0.006$ Rosenbaum score ${ }^{18}$ The marginal effect evaluated at the mean of the Rosenbaum score $($ Mean $=29.99)$ approximates to 0.395 . That is, if contribution by others to the public good increases by one unit, then a participant increases contribution to the public good by 0.395 units. The marginal effect evaluated at one standard deviation (std. dev. $=19.94)$ above the mean Rosenbaum score approximates to a marginal effect of 0.515 , which corresponds to a $30 \%$ increase.

We turn next to a robustness analysis, which also serves to illustrate our results; we plot average contributions for increasing levels of each independent variable. The average contributions are presented in Figures 2-4 for the isolated, standard and interrelated treatments, respectively. Figures 2 and 3 show that conditional contributions rise with Others. This corresponds to the standard observation in public goods experiments, and to Prediction

\footnotetext{
${ }^{18}$ The marginal effect of Others is below 1 for all possible values of the Rosenbaum. This means that our estimated model implies imperfect conditional cooperators. A higher Rosenbaum brings participants closer to perfect conditional cooperators.
} 
2. Notably, those figures show no discernable association between conditional contributions and the Rosenbaum. Figure 4, reveals a similar sensitivity to Others. However, consistent with Prediction 3, the positive association between Others and contributions appears stronger for the two highest levels of Rosenbaum. Moreover, there is no association between Rosenbaum and contributions for the lowest level of Others, but a fairly strong positive association for the highest level of Others. The highest level of cooperation in the Interrelated treatment occurs when both the Rosenbaum and Others take high values.

\section{Insert Figure 2 about here}

Insert Figure 3 about here

\section{Insert Figure 4 about here}

We next to turn our conflict variable, denoted Conflict, which offers the opportunity for a treatment check. Participants reported mean Conflict levels of 47.11 (std. dev. $=32.98)$, 68.08 (std. dev. $=39.57)$, and $61.70($ std. dev. $=42.55)$, in the isolated, standard, and interrelated treatments, respectively. A Kruskal-Wallis test reveals no equality in distributions, $p<0.05$. Of particular interest to us is the difference between the isolated and interrelated treatments, $p<0.1$ (Mann-Whitney $U$ ). ${ }^{19}$ This provides additional (though weak) evidence that our treatments successfully manipulated conflict identification.

Furthermore, because our experimental treatments were intended to manipulate conflict identification, we could run an alternative regression that substitutes the Conflict variable for our treatment variables. Accordingly, specification (11) resembles specification (10) (see Table 3), with the exception that the former features Conflict rather than the treatment variables. While the three-way interaction between Rosenbaum, Others, and Conflict is in the predicted direction (positive), it is not significant. We explore the data further, in Table 4, where we examine the two-way interaction between Rosenbaum and Conflict across different intervals of Others. For the two lowest intervals, the interaction is not significant-but for the three highest, it is positive and significant ( $p$ 's $<0.1,0.1$, and 0.05 , respectively). Overall, the pattern is conceptually consistent with that obtained by Kocher et al. (2012).

\footnotetext{
${ }^{19} \mathrm{~A} t$-test yields significance at the 0.05 -level for the difference between the isolated and the interrelated treatment. The difference between the isolated and standard treatment is significant $(p<0.05)$, but that between the standard and interrelated treatment is not (both Mann-Whitney $U$ ).
} 
Our final analysis of conditional cooperation concerns the distribution of contributor types, classified according to the standard approach (see e.g., Fischbacher et al., 2001; Fischbacher \& Gächter, 2010). Conditional cooperators submitted a contribution schedule with a (weakly, with at least one strict step) monotonically increasing contribution for an increasing average contribution by the other group members. ${ }^{20}$ Free-riders indicated zero conditional contributions for every possible average contribution by the other members. Hump-shape contributors (also known as Triangle contributors) reported (weakly, with at least one strict step) monotonically increasing contributions up to a certain average level of others' contributions, above which their contributions schedule is (weakly, with at least one strict step) monotonically decreasing. The category referred to as Residual comprises the remaining participants. ${ }^{21}$ Our data, across conditions, yields a distribution of types - shown in Table 5-within the range of those found in past studies (e.g., Fischbacher et al., 2001; Kocher et al., 2008; Herrman \& Thöni, 2009; Thöni et al., 2009; Fischbacher \& Gächter, 2010).

\section{Insert Table 5 about here}

As in Kocher et al. (2012), our model makes a prediction about the likelihood that Freeriders relative to other types have identified self-control conflict. Specifically, given that Free-riders - who by definition have contributed less-exhibit similar levels of trait selfcontrol, they should be less likely to have identified the conflict between keeping the money and contributing, and so less likely to have drawn on their self-control strategies to promote pro-social behavior. Indeed, consistent with this prediction, free-riders reported a significantly lower average level of conflict than did other types $(p<0.01$; Mann-Whitney- $U$ ). We thus conclude, like Kocher et al. (2012), that free-riders seem to have contributed less because they were less likely to see a self-control conflict and, therefore, less likely to draw on their selfcontrol strategies to promote pro-social behavior.

\footnotetext{
${ }^{20}$ We also included those without a weakly monotonically increasing contribution, but with a highly significant $(p<0.01)$ positive Spearman rank correlation coefficient between own and others' contributions (see Fischbacher et al., 2001; Fischbacher \& Gächter, 2010).

${ }^{21}$ This category is usually referred to in the literature as Others, but we choose a different label to avoid confusion with the regression variable, which bears the same name.
} 


\subsection{Unconditional contributions}

We next turn to our OLS analysis of unconditional contributions, given in Table 6.

\section{Insert Table 6 about here}

Consistent with Prediction 1, specification (19) reveals that the Rosenbaum exhibits a positive and significant correlation $(p<0.1)$ with unconditional contributions for individuals in the interrelated treatment, who were relatively more likely to identify self-control conflict than were those in the isolated treatment. ${ }^{22}$ However, among those in the isolated treatmentspecification (17) - there is no significant correlation between Rosenbaum and unconditional contributions. The result is summarized below, in Result 1b, corresponding to Prediction 1:

RESULT 1b: In the interrelated treatment, there is a positive association between levels of trait self-control and unconditional cooperation, but there is no discernable association in the isolated treatment.

Furthermore, we conducted an auxiliary test, reported in Table 7, to verify consistency with the corresponding pattern of correlations obtained in Kocher et al. (2012). The interaction in specification (21) between Rosenbaum and conflict intensity shows that the positive correlation between unconditional contributions and trait self-control is stronger $(p<$ 0.05) among participants who reported stronger feelings of conflict-and who were presumably more likely to have identified self-control conflict.

\section{Insert Table 7 about here}

\section{Discussion}

We have tested the hypothesis that identification of self-control conflict gives rise to a stronger positive correlation between self-control and cooperation. In a standard public good

\footnotetext{
${ }^{22}$ In Table 7, specification (20), which includes dummy variables for treatments and the appropriate interaction terms, indicates significance at the 0.05 -level. Although specification (20) is more powerful, we chose to present the results in Table in 6-broken down by treatments-for expositional purposes.
} 
experiment, we find that trait self-control is positively associated with cooperation in the framing treatment that facilitate identification of self-control conflict, but we find no discernable association in the treatment that does not. Our results hold both for conditional and unconditional cooperation; the self-serving bias - the discrepancy between conditional contributions and the contributions by other players-is lower for higher levels of trait selfcontrol. Furthermore, we find that free-riders are characterized not by lacking trait selfcontrol, but by appearing not to have perceived the self-control conflict in the first place. Overall, our results suggest that self-control benefits cooperation.

Our results are consistent with recent work by Martinsson et al. (2012), who employ an identical framing treatment in the dictator game; they find that trait-self control, captured on the same psychometric scale (Rosenbaum, 1980a), is positively associated with donations in the treatment that facilitates identification - but that there is no association in the treatment that does not. Moreover, our results extend those obtained by Kocher et al. (2012), who test in the public good game a more general model of self-control and pro-social behavior. Their empirical procedure includes the Rosenbaum measure of self-control and a risk elicitation procedure. However, they did not employ experimental treatments to influence perception of self-control conflict-instead they relied on individuals' self-reports of experienced conflict. Their findings, therefore, leave open questions of causality, and it was our objective here to explore that of conflict identification. Not only do we find evidence for the causal story theorized by Kocher et al. (2012), we also replicate across our treatments their pattern of correlations.

Moreover, our results are consistent with a number of other findings in the literature, perhaps most notably that contributions to the public good are negatively associated with discount rates (Curry et al., 2008; Fehr \& Leibbrandt, 2011). However, our results speak against the general hypothesis, put forward by Rand et al. (2012), that cooperation is 'intuitive' and greed 'calculated'. In fact, the literature on the relation between cognitive resources and cooperation offers mixed results (e.g., Duffy \& Smith, 2012; Tinghög et al., 2013; Lohse et al., 2014; Rand et al., 2014) — as does the literature on cognitive resources and giving (e.g., Hauge et al., 2009; Schulz et al., 2014; Achtziger et al., 2014a).

On the question of generality, therefore, we echo a note of humility from Martinsson et al. (2012). While our present results do suggest that individuals are tempted to be selfish and that higher levels of self-control will benefit cooperation, there is good reason to think that the pattern under other circumstances might reverse. In particular, when the beneficiaries of the 
public good are concrete, triggering feelings of empathy, the urge to cooperate might conflict with a better judgment to cooperate less. For example, the diligent student who feels sorry for her poorly performing group members might feel compelled to do everything in a group project that awards the same grade to every group member. In our experiment, however, the beneficiaries are anonymous and hence highly abstract - as is standard in the public good game - and therefore unlikely to evoke empathetic urges.

Following a similar logic, our conceptual framework may aid in understanding why recent studies have found that individuals actively eschew opportunities to donate to others (e.g., Dana et al., 2006; Broberg et al., 2007; Andreoni et al., 2011; Knutsson et al., 2013). Knowing that a donation opportunity will present itself, it is possible that individuals may anticipate feeling pressured to give and thus identify a potential self-control conflict. The pressure might arise from empathy, as when facing a solicitor (e.g., in Androni et al., 2011), or, when confronted with a charity donation request, from social norm activation (Knutsson et al., 2013). In either case, the individual might resolve to preempt the self-control conflict by engaging a pre-commitment technology, thereby avoiding the difficult donation decision altogether.

A critic might respond that our framework is too flexible, in that it allows the directionality of the temptation to go either way, and by implication, pre-commitment decisions to do the same. How then could we resolve the question as to which behavior constitutes the human "universal" default? Given the disparate findings in the literature, and our basic understanding of cognitive processes, we would maintain that the flexibility of our framework is necessary. The problem, then, might not be our framework - but the question; it may not be meaningful to speak of a universal default to be selfish or cooperative. Similarly, it may not be meaningful to argue, as some recently have, that one or the other is more intuitive. Our results and theoretical framework, together with an extensive literature in psychology and economics, suggest that the question of which is more intuitive-whether one or the other constitutes a "default"-will depend very much on the context at hand.

We end by noting that the relationship between cooperation and self-control has implications for the study of strategic interaction more generally. If self-control determines cooperation, self-control may also determine players' strategic concerns in other interactions, where the choice of one player affects the welfare of others. An exploration into the role of self-control in strategic interaction should prove fruitful. 


\section{References}

Aaker, J., Drolet, A., \& Griffith, D. (2008). Recalling mixed emotions: How did I feel again? Journal of Consumer Research, 35, 268-278.

Achtziger, A., Alós-Ferrer, C., \& Wagner, A. K. (2014a). Money, depletion, and prosociality in the dictator game. Working paper, University of Cologne.

Achtziger, A., Alós-Ferrer, C., \& Wagner, A. K. (2014b). Social preferences and self-control. Working Paper, University of Cologne.

Aguilar-Pardo, D., Martínez-Arias, R., \& Colmenares, F. (2013). The role of inhibition in young children's altruistic behaviour. Cognitive Processing, 14, 301-307.

Albrecht, K., Laibson, D. I., Sutter, M., Volz, K. G., \& von Cramon, D. Y. (2011). What is for me is not for you: Brain correlates of intertemporal choice for self and other. Social Cognitive and Affective Neuroscience, 6, 218-225.

Alós-Ferrer, C., \& Strack, F. (2014). From dual processes to multiple selves: Implications for economic behavior. Journal of Economic Psychology, 41, 1-11.

Anderson, S., Goeree, J., \& Holt, C. (1998). A theoretical analysis of altruism and decision error in public goods games. Journal of Public Economics, 70, 297-323.

Andreoni, J. (1990). Impure altruism and donations to public goods: A theory of warm-glow giving. Economic Journal, 85, 891-904.

Andreoni, J. (1995). Cooperation in public goods experiments: Kindness or confusion? American Economic Review, 85, 891-904.

Andreoni, J. (2006). Philanthropy. In S.-C. Kolm, \& J. M. Ythier (Eds). Handbook of the Economics of giving, reciprocity, and altruism 2 (pp. 1201-1269). Amsterdam: Elsevier.

Andreoni, J., Rao, J.M., \& Trachtman, H. (2011). Avoiding the ask: A field experiment on altruism, empathy and charitable giving. Working Paper. UC San Diego 
Ariely, D., Bracha, A., \& Meier, S. (2009). Doing good or doing well? Image motivation and monetary incentives in behaving prosocially. American Economic Review, 99, 544-555.

Ayduk, O., Mendoza-Deonton, R., Mischel, W., Downey, G., Peake, P. K., \& Rodriguez, M. (2000). Regulating the interpersonal self: Strategic self-regulation for coping with rejection sensitivity. Journal of Personality and Social Psychology, 79, 776-792.

Baumeister, R. F., Bratslavsky, E., Muraven, M., \& Tice, D. M. (1998). Ego-depletion: Is the active self a limited resource? Journal of Personality and Social Psychology, 74, 12521265.

Baumeister, R. F., Heatherton, T. F., \& Tice, D. M. (1994). Losing control: How and why people fail at self-regulation. San Diego, CA: Academic Press.

Broberg, T., Ellingsen, T., \& Johannesen, M. (2007). Is generosity involuntary? Economics Letters, 94, 32-37.

Burger, N., Charness, G., \& Lynham, J. (2011). Field and online experiments on self-control. Journal of Economic Behavior and Organization, 77, 393-404.

Burks, S. V., Carpenter, J. P., Goette, L., \& Rustichini, A. (2009). Cognitive skills affect economic preferences, strategic behavior, and job attachment. Proceedings of the National Academy of Sciences, 106, 7745-7750.

Bénabou, R., \& Tirole, J. (2006). Incentives and prosocial behavior. American Economic Review, 96, 1652-1678.

Bénebou, R., \& Tirole, J. (2011). Identity, morals, and taboos: Beliefs as assets. Quarterly Journal of Economics, 126, 805-855.

Capafóns, A. (1989). Competencia aprendida: Fiabilidad y validez de su medida, críticas y recomendaciones. Revista Española de Terapia del Comportamiento, 7, 19-39. 
Cornellisen, G., Dewitte, S., \& Warlop, L. (2011). Are social value orientations expressed automatically? Decision making in the dictator game. Personality and Social Psychology Bulletin, 37, 1080-1090.

Crocket, M. J., Clark, L., Tabibnia, G., Lieberman, M. D., \& Robbins, T. W. (2008). Serotonin modulates behavioral reactions to unfairness. Science, 320, 1739.

Crocket, M. J., Clark, L., Tabibnia, G., Lieberman, M. D., \& Robbins, T. W. (2010). Impulsive choice and altruistic punishment are correlated and increase in tandem with serotonin depletion. Emotion, 10, 855-862.

Curry, O. S., Price, M. E., \& Price, J. G. (2008). Patience is a virtue: Cooperative people have lower discount rates. Personality and individual differences, 44, 780-785.

Chaudhuri, A. (2011). Sustaining cooperation in laboratory public goods experiments: A selective survey of the literature. Experimental Economics, 14, 47-83.

Dana, J., Cain, D. M., \& Dawes, R. M., 2006. What you don't know won't hurt me: costly (but quiet) exit in dictator games. Organizational Behavior and Human Decision Processes, 100, 193-201.

Duckworth, A. L., \& Seligman, M. E. P. (2005). Self-discipline outdoes IQ in predicting academic performance of adolescents. Psychological Science, 16, 939-944.

Duffy, S., \& Smith, J. (2012). Cognitive load in the multi-player prisoner's dilemma game. MPRA Paper No. 35906, LMU.

Eigsti, I., Zayas, V., Mischel, W., Shoda, Y., Ayduk, O., Dadlani, M. B., Davidson, M. C., Aber, J. L., \& Casey, B. J. (2006). Predictive cognitive control from preschool to late adolescence and young adulthood. Psychological Science, 17, 478-484.

Fehr, E., \& Leibbrandt, A. (2011). A field study on cooperativeness and impatience in the tragedy of the commons. Journal of Public Economics, 95, 1144-1155. 
Fehr, E., \& Schmidt, K. (1999). A theory of fairness, competition and cooperation. Quarterly Journal of Economics, 114, 817-868.

Fehr, E., \& Schmidt, K. M. (2006). The economics of fairness, reciprocity and altruism: Experimental evidence and new theories. In Kolm, S., \& J.M. Ythier (Eds). Handbook of the economics of giving, altruism and reciprocity 1 (pp. 615-691). Amsterdam: Elsevier.

Fischbacher, U., Gächter, S., \& Fehr, E. (2001). Are people conditionally cooperative? Evidence from a public goods experiment. Economics Letters, 71, 397-404.

Fischbacher, U., \& Gächter, S. (2010). Social preferences, beliefs, and the dynamics of free riding in public good experiments. American Economic Review, 100, 546-665.

Fischbacher, U., Gächter, S., \& Quercia, S. (2012). The behavioral validity of the strategy method in public good experiments. Journal of Economic Psychology, forthcoming.

Frederick, S., Loewenstein, G., \& O’Donoghue, T. (2002). Time discounting and time preference: A critical review. Journal of Economic Literature, 15, 351-401.

Fudenberg, D., \& Levine, D. K. (2006). A dual-self model of impulse control. American Economic Review, 96, 1449-1476.

Fudenberg, D., Levine, D. K., \& Maniadis, Z. (2014). An approximate dual-self model and paradoxes of choice under risk. Journal of Economic Psychology, 41, 55-67.

Gneezy, A., Imas, A., Brown, A., Nelson, L. D., \& Norton, M. I. (2012). Paying to be nice: Consistency and costly pro-social behavior. Management Science, 58, 179-187.

Gächter, S. (2007). Conditional cooperation. Behavioral regularities from the lab and the field and their policy implications. In Frey, B., \& Stutzer, A. (Eds). Economics and Psychology. A promising new cross-disciplinary field. CESifo seminar series. Cambridge, MA: MIT Press. 
Halali, E., Bereby-Meyer, Y., \& Ockenfels, A. (2013). Is it all about the self? The effect of self-control depletion on ultimatum game proposers. Frontiers in Human Neuroscience, doi: 10.3389/fnhum.2013.00240..

Hauge, K. E. (2010). Morality and economic decisions: An experimental approach. PhDthesis, Department of Economics, University of Oslo.

Hauge, K. E., Brekke, K. A., Johansson, L., Johansson- Stenman, O., \& Svedsäter, H. (2009). Are social preferences skin deep? Dictators under cognitive load. Working Papers in Economics 371, University of Gothenburg.

Herrmann, B., \& Thöni, C. (2009). Measuring conditional cooperation: A replication study in Russia. Experimental Economics, 12, 87-92.

Houser, D. \& Kurzban, R. (2002). Revisiting kindness and confusion in public goods experiments. American Economic Review, 92, 1062-1069.

Hofmann, W., Friese, M., \& Strack, F. (2009). Impulse and self-control from a dual-systems perspective. Perspectives on Psychological Science, 4, 162-176.

Katz, R. C. \& Singh, N. (1986). A comparison of current smokers and self-cured quitters on Rosenbaum's self-control schedule. Addictive Behaviors, 11, 63-65.

Kahneman, D. (2003). A perspective on judgment and choice: Mapping bounded rationality. American Psychologist, 58, 697-720.

Keser, C., \& van Winden, F. (2000). Conditional cooperation and voluntary contributions to public goods. Scandinavian Journal of Economics, 102, 23-39.

Knoch, D., Pascual-Leone, A., Meyer, K., Treyer, V., \& Fehr, E. (2006). Diminishing reciprocal fairness by disrupting the right prefrontal cortex. Science, 314, 829-832.

Knutsson, M., Martinsson, P., \& Wollbrant, C. (2013). Do people avoid opportunities to donate? A natural field experiment on recycling and charitable giving. Journal of Economic Behavior and Organization, 93, 71-77. 
Knoch, D., Schneider, F., Schunk, D., Hohmann, M., \& Fehr, E. (2009). Disrupting the prefrontal cortex diminishes the human ability to build a good reputation. Proceedings of the National Academy of Sciences, 106, 20895-20899.

Kocher, M. G., Cherry, T., Kroll, S., Netzer, R. J., \& Sutter, M. (2008). Conditional cooperation on three continents. Economics Letters, 101, 175-178.

Kocher, M. G., Martinsson, P., Myrseth, K. O. R., Wollbrant, C. (2012). Strong, bold and kind: Self-control and cooperation in social dilemmas. Working Papers in Economics 523, University of Gothenburg.

Laibson, D. I. (1997). Golden eggs and hyperbolic discounting. Quarterly Journal of Economics, 112, 443-477.

Ledyard, J. O. (1995). Public goods: A survey of experimental research. In Kagel, J., \& Roth, A. (Eds). The handbook of experimental economics (pp. 111-194). Princeton, NJ: Princeton University Press.

Liebrand, W. B. G. (1984). The effect of social motives, communication and group size on behaviour in a N-person multi-stage mixed-motive game. European Journal of Personality, 14, 139-364.

List, J. (2008). Introduction to field experiments in economics with applications to the economics of charity. Experimental Economics, 11, 203-212.

Loewenstein, G. (1996). Out of control: Visceral influences on behavior. Organizational Behavior and Human Decision Processes, 65, 272-292.

Loewenstein, G. (2000). Preferences, behavior and welfare: Emotions in economic theory and economic behavior. American Economic Review, 90, 426-432.

Lohse, J., Goeschl, T., \& Diederich, J. (2014). Giving is a question of time: Response times and contributions to a real world public good. Discussion Paper Series No. 566, Department of Economics, University of Heidelberg. 
Lotito, G., Migheli, M., \& Ortona, G. (2013). Is cooperation instinctive? Evidence from the response times in a public goods game. Journal of Bioeconomics, 15, 123-133.

March, J. G. (1994). A primer of decision making: How decisions happen. New York: Free Press.

Martinsson, P., Myrseth, K. O. R., \& Wollbrant, C. (2012). Reconciling pro-social vs. selfish behavior: On the role of self-control. Judgment and Decision Making, 7, 304-315.

Metcalfe, J., \& Mischel, W. (1999). A hot/coolsystem analysis of delay of gratification: Dynamics of willpower. Psychological Review, 106, 3-19.

Messick, D. (1999). Alternative logics for decision making in social settings. Journal of Economic Behavior and Organization, 39, 11-28.

Milgram, N. A., Sroloff, B., \& Rosenbaum, M. (1988). The procrastination of everyday life. Journal of Research in Personality, 22, 197-212.

Miller, E. K., \& Cohen, J. D. (2001). An integrative theory of prefrontal cortex function. Annual Review of Neuroscience, 24, 167-202.

Mischel, W., Shoda, Y., \& Peake, P. K. (1988). The nature of adolescent competencies predicted by preschool delay of gratification. Journal of Personality and Social Psychology, 54, 687-696.

Mischel, W., Shoda, Y., \& Rodriguez, M. L. (1989). Delay of gratification in children. Science, 244, 933-938.

Myrseth, K. O. R., \& Fishbach, A. (2009). Self-control: A function of knowing when and how to exercise restraint. Current Directions in Psychological Science, 18, 247-252.

Myrseth, K. O. R., \& Fishbach, A. (2010). Seeing self-control conflict: The problem of isolated vs. interrelated temptations. Working paper, the University of Chicago.

Myrseth, K. O. R., \& Wollbrant, C. (2013). A theory of self-control and naïveté: The blights of willpower and blessings of temptation. Journal of Economic Psychology, 34, 8-19. 
Myrseth, K. O. R., Riener, G., \& Wollbrant, C. (2013). Tangible temptation in the social dilemma: Cash, cooperation, and self-control. ESMT Working Paper No. 13-04.

Nielsen, U. H., Tyran, J-R., \& Wengström, E. (2014). Second thoughts on free riding. Economics Letters, 122, 13-139.

O’Donoghue, T., \& Rabin, M. (1999). Doing it now or later? American Economic Review, 89, 103-24.

O’Donoghue, T., \& Loewenstein, G. (2007). The heat of the moment: Modeling interactions between affect and deliberation. Working paper, Cornell University, Ithica, New York.

Palfrey, T. R., \& Prisbrey, J. E. (1997). Anomalous behavior in public goods experiments: how much and why? American Economic Review, 87, 829-846.

Piovesan, M., \& Wengström, E. (2009). Fast or fair? A study of response times. Economics Letters, 105, 193-196.

Pronin, E., Olivola, C. Y., \& Kennedy, K. A. (2008). Doing unto future selves as you would do unto others: Psychological distance and decision making. Personality and Social Psychology Bulletin, 34 224-236.

Rachlin, H. (2004). The science of self-control. United States of America: First Harvard University Press.

Rand, D. G., Greene, J. D., \& Nowak, M. A. (2012). Spontaneous giving and calculated greed. Nature, 489, 427-430.

Rand, D. G., Peysakhovich, A., Kraft-Todd, G. T., Newman, G. E., Wurzbacher, O., Nowak, M. A., \& Greene, J. D. (2014). Social heuristics shape intuitive cooperation. Nature Communications, 5, 3677. DOI: 10.1038/ncomms4677.

Romal, J. B., \& Kaplan, B. J. (1995). Difference in self-control among spenders and savers. Psychology: A journal of human behavior, 32, 8-17. 
Rosenbaum, M. (1980a). A schedule for assessing self-control behaviors: Preliminary findings. Behavior Therapy, 11 109-121.

Rosenbaum, M. (1980b). Individual differences in self-control behaviors and tolerance of painful stimulation. Journal of Abnormal Psychology, 89, 581-590.

Rosenbaum, M. (1989). Self-control under stress: The role of learned resourcefulness. Advances in Behavior Research and Therapy, 11, 249-258.

Rosenbaum, M., \& Rolnick, A. (1983). Self-control behaviors and coping with seasickness. Cognitive Therapy and Research 7 93-97.

Rosenbaum, M., \& Palmon, N. (1984). Helplessness and resourcefulness in coping with epilepsy. Journal of Consulting and Clinical Psychology, 52, 244-253.

Rosenbaum, M., \& Smira, B. K. (1986). Cognitive and personality factors in the delay of gratification of hemodialysis patients. Journal of Personality and Social Psychology, $51,357-364$.

Rubinstein, A. (2007). Instinctive and cognitive reasoning: A study of response times. Economic Journal, 117, 1243-1259.

Schelling, T. (1984). Self-command in practice, in policy, and in a theory of choice. American Economic Review, 74, 1-11.

Schulz, J. F., Fischbacher, U., Thöni, C., \& Utikal, V. (2014). Affect and fairness: Dictator games under cognitive load. Journal of Economic Psychology, 41, 77-87.

Selten, R. (1967). Die Strategiemethode zur Erforschung des eingeschränkt rationalen Verhaltens im Rahmen eines Oligopolexperiments. In Sauerman, H. (Ed). Beiträge zur experimentellen Wirthchaftsforschung, Vol. I (pp. 136-168). Tübingen: Mohr.

Shoda, Y., Mischel, W., \& Peake, P. K. (1990). Predicting adolescent cognitive and social competence from preschool delay of gratification: Identifying diagnostic conditions. Development Psychology, 26, 392-406. 
Sloman, S. A. (1996). The empirical case for two systems of reasoning. Psychological Bulletin, 11, 3-22.

Stanovich, K. E., \& West, R. F. (2000). Individual differences in reasoning: Implications for the rationality debate. Behavioral and Brain Sciences, 23, 645- 665.

Strotz, R. H. (1955). Myopia and inconsistency in dynamic utility maximization. Review of Economic Studies, 23, 165-180.

Schweighofer, N., Bertin, M., Shishida, K., Okamoto, Y., Tanaka, S. C., Yamawaki, S., \& Doya, K. (2008). Low serotonin levels increase delayed reward discounting in humans. Journal of Neuroscience, 28, 4528-4532.

Thaler, R. H., \& Shefrin, H. M. (1981). An economic theory of self-control. Journal of Political Economy, 89, 392-406.

Tinghög, G., Andersson, D., Bonn, C., Böttiger, H., Josephson, C., Lundgren, G., Västfjäll, D., Kirchler, M., \& Johannesson, M. (2013). Intuition and cooperation reconsidered. Nature, 498, E1-E2.

Weber, J., Kopelman, S., \& Messick, D. (2004). A conceptual review of decision making in social dilemmas: Applying a logic of appropriateness. Personality and Social Psychology Review, 8, 281-307.

Zelmer, J. (2003). Linear public goods experiments: A meta-analysis. Experimental Economics, 6, 299-310. 
Table 1: Summary statistics

\begin{tabular}{|c|c|c|c|c|c|c|}
\hline Variable label & Description & $\begin{array}{l}\text { Number of } \\
\text { obs. }\end{array}$ & Mean & $\begin{array}{l}\text { Std. } \\
\text { Dev. }\end{array}$ & Min & $\operatorname{Max}$ \\
\hline Unconditional contribution & $\begin{array}{l}\text { Unconditional contribution to the } \\
\text { public good }\end{array}$ & 156 & 8.17 & 6.27 & 0 & 20 \\
\hline Conditional contribution* & $\begin{array}{l}\text { Conditional contribution to the public } \\
\text { good }\end{array}$ & 3297 & 5.41 & 6.06 & 0 & 20 \\
\hline Others & $\begin{array}{l}\text { A vector of integer numbers between } \\
\text { and including } 0 \text { and } 20 \text {, indicating all } \\
\text { possible average contributions of the } \\
\text { three other group members in the } \\
\text { conditional contribution task }\end{array}$ & 3297 & 10 & 6.06 & 0 & 20 \\
\hline Conflict & $\begin{array}{l}\text { Response to "To what extent did you } \\
\text { experience conflict when deciding how } \\
\text { much to contribute?" ranging from } 0 \\
\text { ("Not at all") and } 140 \text { ("Very much") }\end{array}$ & 157 & 58.45 & 39.20 & 0 & 140 \\
\hline Rosenbaum & $\begin{array}{l}\text { The Rosenbaum Self-Control Schedule } \\
\text { Score }\end{array}$ & 154 & 29.71 & 19.90 & -16 & 77 \\
\hline Isolated & $\begin{array}{l}\text { Isolated treatment presenting a } \\
\text { calendar with a grid separating the } \\
\text { dates prior to the contribution decision }\end{array}$ & 157 & 0.36 & 0.48 & 0 & 1 \\
\hline Standard & $\begin{array}{l}\text { Standard treatment presenting no } \\
\text { calendar prior to the contribution } \\
\text { decision }\end{array}$ & 157 & 0.31 & 0.46 & 0 & 1 \\
\hline Interrelated & $\begin{array}{l}\text { Interrelated treatment presenting a } \\
\text { calendar without a grid separating the } \\
\text { dates prior to the contribution decision }\end{array}$ & 157 & 0.34 & 0.47 & 0 & 1 \\
\hline
\end{tabular}

Note: * Denotes a variable constructed using the strategy method. 